\title{
Digitalised exercise material in forensic odontology
}

\author{
Ina C. Knivsberg ${ }^{1} \cdot$ Simen E. Kopperud ${ }^{1,2}$ - Mai-Britt Bjørk ${ }^{1}$ - Gerald Torgersen ${ }^{1} \cdot$ Katarzyna Skramstad $^{1}$. \\ Sigrid I. Kvaal ${ }^{1}$
}

Received: 15 August 2021 / Accepted: 28 October 2021 / Published online: 20 November 2021

(C) The Author(s) 2021

\begin{abstract}
Introduction This paper presents digital educational material in forensic odontology, including dental identification after multiple fatalities and dental age estimation from different age groups.

Material and method Electronic patient records consisting of intraoral scans of the dentition, digital radiographs, photographs and written dental records were collected. Exercises in age estimations contained digital radiographs and photographs of ground tooth sections, with digital measuring tools and tables according to age groups. The teaching material was organised as a module in an electronic Learning Management System with external links to all relevant teaching material.

Results For the identification exercises, intraoral scans and the latest digital radiographs simulated the postmortem examination of the deceased. For comparison, all other radiographs, photographs and dental records were available as antemortem material. The exercise was to match postmortem findings with the antemortem records using the Interpol standard and reconciliation. Age assessment of children used designated tables to grade tooth development on digital radiographs. For adults, non-destructive methods, digital radiographs, photographs and measuring tools were used.

Discussion The teaching concept was hybrid, but it can easily be adapted as a fully digital exercise. The instructions and written material can be translated into different languages. The level of difficulty in the exercises can be adjusted according to the participant's level of knowledge.

Conclusion The educational material embraces the new possibilities for digitalisation and intraoral scanning. This might be a valuable tool for motivating and engaging the students in their participation and understanding of the subject.
\end{abstract}

Keywords Hybrid learning $\cdot$ Digitalised teaching $\cdot$ Intraoral scanning $\cdot$ Forensic education

$\begin{array}{ll}\text { Abbreviations } \\ \text { 3D } & \text { three-dimensional } \\ \text { AM } & \text { antemortem } \\ \text { EU } & \text { European Union } \\ \text { EEA } & \text { European Economic Area } \\ \text { FO } & \text { forensic odontology } \\ \text { GDPR } & \text { General Data Protection Regulation } \\ \text { IOS } & \text { intra oral scans } \\ \text { LMS } & \text { learning management system } \\ \text { PAN } & \text { panoramic radiographs } \\ \text { PM } & \text { postmortem } \\ \text { PDF } & \text { portable document format }\end{array}$

Ina C. Knivsberg

inackn@odont.uio.no

University of Oslo, Oslo, Norway

2 Norwegian Armed Forces Joint Medical Services, Dental Division, Oslo, Norway

\section{Introduction}

Forensic odontology (FO) or forensic dentistry applies dental knowledge to criminal and civil laws enforced by police agencies in a criminal justice system. Investigative agencies may request assistance from a forensic odontologist to identify recovered human remains $[1,2]$. General dental practitioners may be asked to assist the forensic odontologist. Many dental schools have included a general introduction to FO in the undergraduate curriculum [3-6].

Dental identification of human remains implies comparing dental records from a missing person with the deceased's dental status. The dental record, generally a chronological series of treatment details, is transcribed to a status record, the antemortem (AM) record. Following the examination of the remains, the body's dental status is registered as the postmortem (PM) record. Matching records AM and PM may provide dental identification [7]. Since 1984, Interpol has published and revised standards for human identification. It 
may be established by comparing AM and PM data collected from either fingerprints, dental examinations, DNA analyses and/or physical indicators [7].

Dental age estimation is based on dental development from foetal life to young adult [8]. In adults, dental age estimation is based on degenerative changes in the dentition [9]. For the practical part of the FO course, it has previously been recommended that jaws from anatomical dissections are used in addition to transcription or construction of dental records [10-12]. A disadvantage has been that the jaws must be returned to the body and new teaching material created every year. As an alternative, dry anatomical specimens have been used. However, with repeated handling, such material deteriorates (Fig. 1). The dental records and analogue radiographs will, over time, be outdated and may not comply with national regulations and recommendations for record-keeping.

The European General Data Protection Regulation (GDPR) was implemented on May 25, 2018, in all member states of the European Union (EU) and the European Economic Area (EEA) to harmonise data privacy laws [12]. GDPR and the Norwegian Act of applying biotechnology in human medicine (The Biotechnology Act 2003) raised the need to renew the teaching material providing identification and age estimation training.

These regulations paved the way for the digitalisation of older material and introduced the extended use of intraoral scanning (IOS).

IOS are either based on contact or non-contact between the object to be captured and the device to transfer information in direct optical impressions. Most scanners used in dentistry are non-contact type. Intraoral scanners use various methods to capture raw data, including confocal microscopy, triangulation, interferometry, wavefront sampling, structured light, laser and video [13]. The scanning software processes the images of the dento-gingival tissues using nonionizing electromagnetic radiation [14]. Digital information on oral structures collected by intraoral scanners can be managed through software tools to generate point clouds that are triangulated to give surface reconstructions, often referred to as meshes [15]. The software creates an STL file (standard tessellation language) and can be communicated to dental laboratories and patients. The scans can also be exported to a Polygon File Format file (PLY) which can be viewed in programmes on most platforms [16]. The 3D surface model is the 'virtual' alternative to the traditional plaster model, but it allows enhancement in magnification, rotation and colour adjustments [17].

\section{Aims}

The purpose of this paper is to present digital educational material for practical exercises in FO.

Two types of exercises are included:

- dental identification after multiple fatalities

- dental age estimation from different age groups.

\section{Materials and methods}

The new teaching concept used patient records from living patients for both AM and PM material. Electronic patient records were collected from private practices and a university dental clinic in Norway. Written consents were

Fig. 1 The educational material used prior to our new digitalised educational programme; lightbox with analogue intraoral radiographs and deteriorated material from human remains

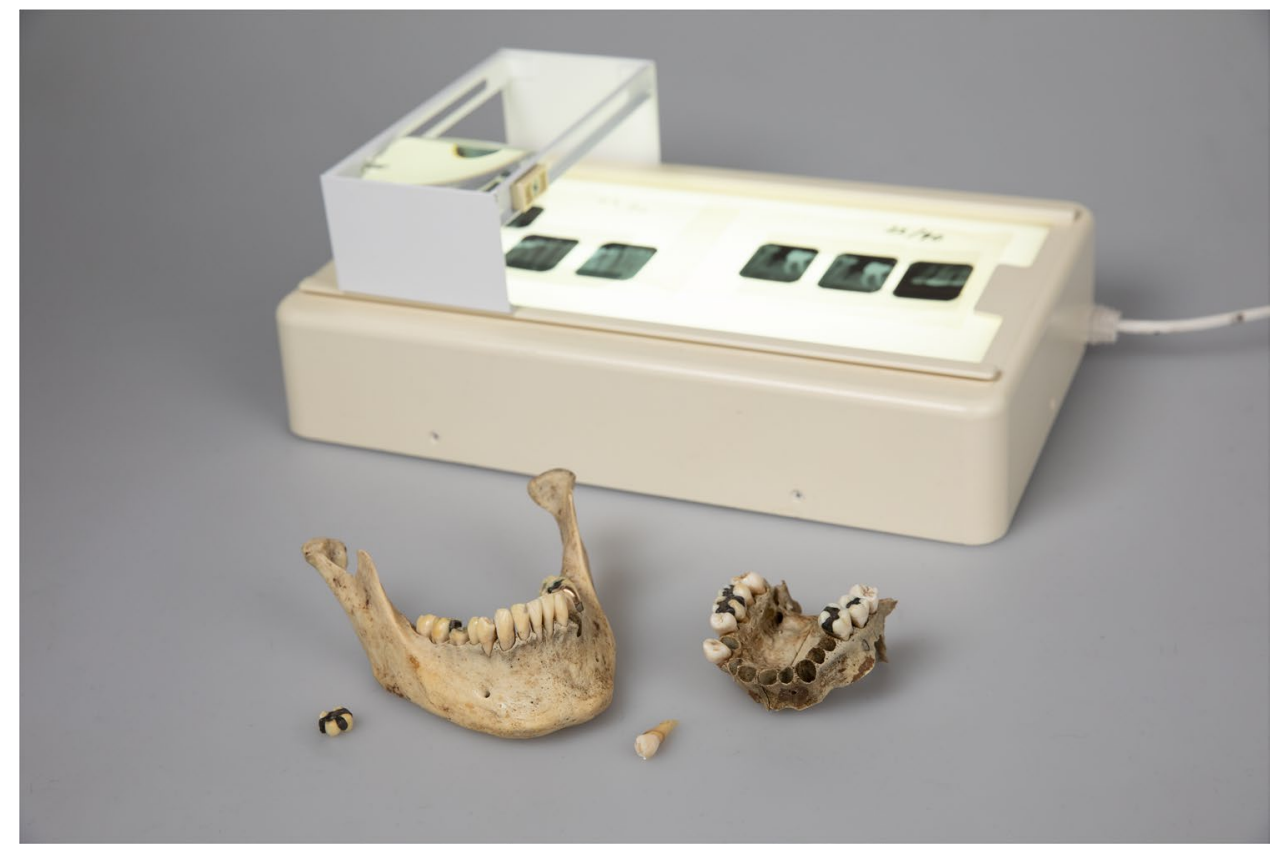


obtained from all participants; no remuneration was given. The patient records consisted of available radiographs, photographs and written dental records from the past 5 years. An intraoral scan (IOS) of the dentition, bitewings and intraoral and extraoral pictures substituted a clinical PM examination of the victim's dentition and characteristic traits.

Using a standardised protocol, intraoral scans were performed with Primescan by Dentsply Sirona (2019) and 3Shape TRIOS 4 (2019). To avoid being dependent on specific software to view these scans, the files were converted to MPEG-4 format using the Adobe Media Encoder software (Adobe Inc. 2020) and Exocad Webview (exocad GmbH 2020). This enabled the students to access the $3 D$ dentition scans as video clips on their computers. Dental records were converted to pdf files, radiographs anonymized using the software ImageJ and the pdfs anonymized with redact function in Adobe Acrobat DC (Adobe Inc. 2020) [18].

Digitalised and anonymized panoramic radiographs and periapical radiographs were used for the exercises in age assessment. For one of the exercises, an extracted tooth (premolar) was donated from a person of known age. The tooth was fixed in epoxy using EpofixResin/Epofix Hardener (Struers, Ballerup, Denmark), sectioned in the sagittal plane in a 1-mm slice using a Struers saw, and then photographed with a Single-Lens Reflex camera next to a millimetre scale. The free mathematics software GeoGebra Math Apps was used to measure given dimensions [19]. It provided intercalibrated measurement facilitating the completion of the digital formulas presented for age estimation.

The University of Oslo has adopted Canvas (Instructure, Inc.) as its standard Learning Management System (LMS). The FO's teaching material was organised as a module in Canvas. It contained external links to all relevant teaching material, including a "user manual" for the assignments, handouts from FO lectures, and general information. The students accessed the material using their laptop computers. At the completion of the exercise, the students were asked to fill out a short evaluation form.

\section{Results}

The implementation of the present teaching material was considered by the Regional Committee for Medical Research Ethics in Norway not to require approval (ID: 2019/460 D).

\section{Included patient records (sample)}

The patient records from 15 females and 16 males had an age span ranging from 12 to 92 years of age. The two groups of collected patient records consisted of regular recall patients from private clinics and referred patients to the specialist clinic at the University. This ensured widespread treatment modalities, sex, age and different record-keeping software, and provided a significant variation in identification markers. For the five age assessment exercises, panoramic and periapical radiographs were anonymized and transferred from analogue to digital format. A photograph visualised apical translucency.

\section{The practical exercise in identification}

Each patient record was split into two separate patient information packages, providing $31 \mathrm{AM}$ packages and 31 corresponding PM packages. The PM packages consisted of the video clip of the intra-oral scan of the dentition, along with the most recent radiographs and oral photographs, resembling the information a forensic dentist would gather during a postmortem examination (Fig. 3a). The AM packages consisted of all other radiographs, photographs and dental records, resembling information that could have been collected from a dental practitioner (Fig. 2a). The AM and PM packages were randomised in a list with a cross-reference security key.

The practical exercise simulated an accident with multiple fatalities. The students' task in the practical exercise was to reconcile a PM case correctly with a matching AM case after downloading editable pdf versions of Interpol's AM and PM forms [7] (Figs. 2b and 3b). Each student received one PM information package and transcribed the information to Interpol's PM form after going through its content. They uploaded the PM form to a shared folder in Canvas. All students then randomly received an AM information package and transcribed the information to Interpol's AM form. Finally, they manually searched the shared folder with PM forms until they found a dentition matching their AM case. They filled in a reconciliation form, uploaded the form to a shared folder in Canvas, and finally, the exercise was reviewed in plenary by use of an identification table (Fig. 4).

\section{Practical exercise in age assessment}

The practical exercise in age assessment consisted of five separate assignments with specific digitalized information packages. This practical exercise aimed to demonstrate some of the principles for age assessment in different age groups, as presented in Table 1 .

Specific methods were suggested for the different age groups. Until the age of 12-14, several teeth are developing, and the students had to evaluate results from two different methods $[20,21]$. When the second molar is fully developed at the age of 16 , the third molar is the only tooth still developing. Two different tables for assessment of wisdom teeth development in relation to age were provided [22, 23].

For the assessment of adults, both a non-destructive and a destructive method were chosen. The non-destructive method 


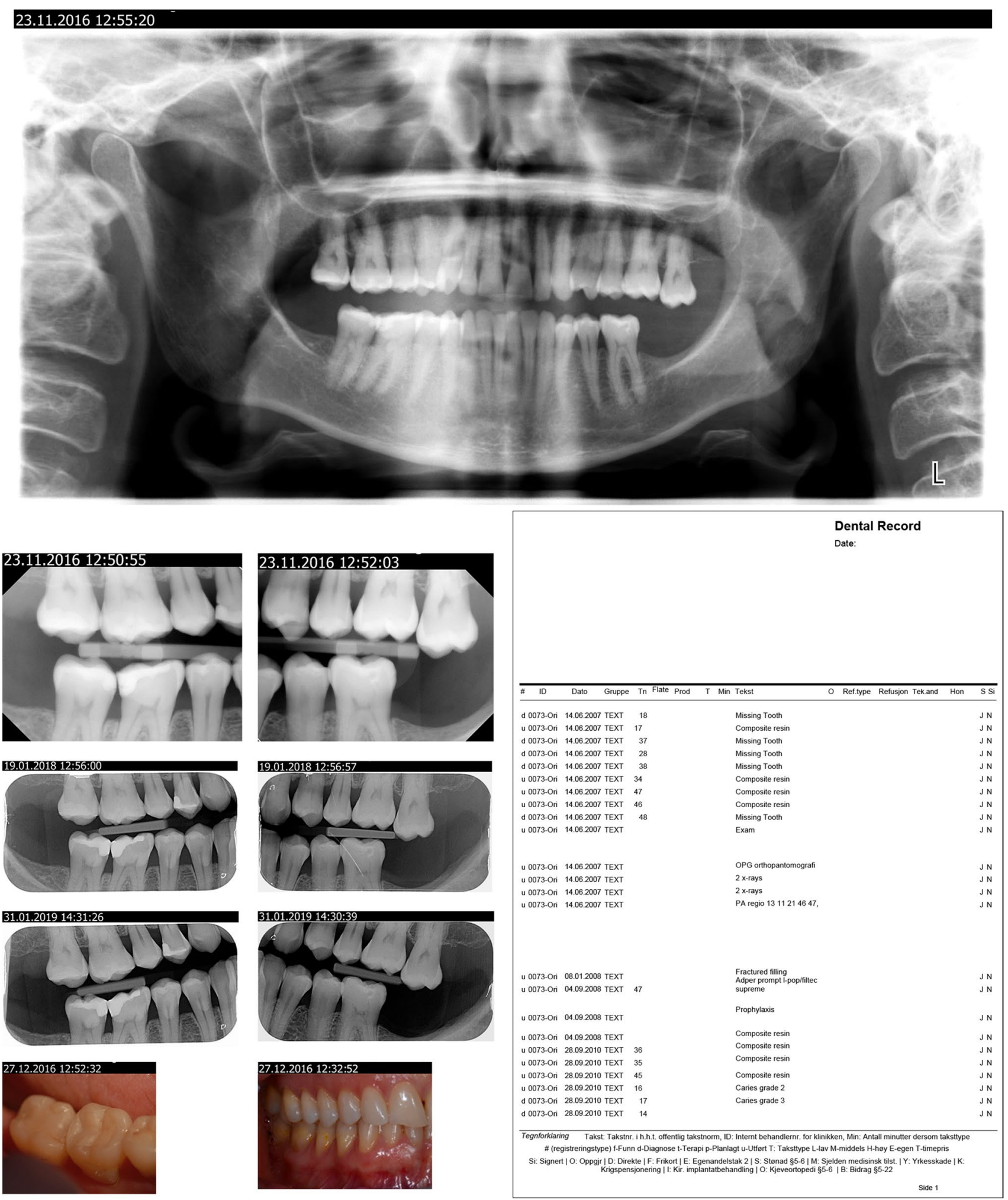

Fig. 2 a AM information package as presented for the students; intraoral pictures, bitewings radiographs, panoramic radiographs, written dental records. b Interpol form, disaster victim identification, missing person antemortem. 

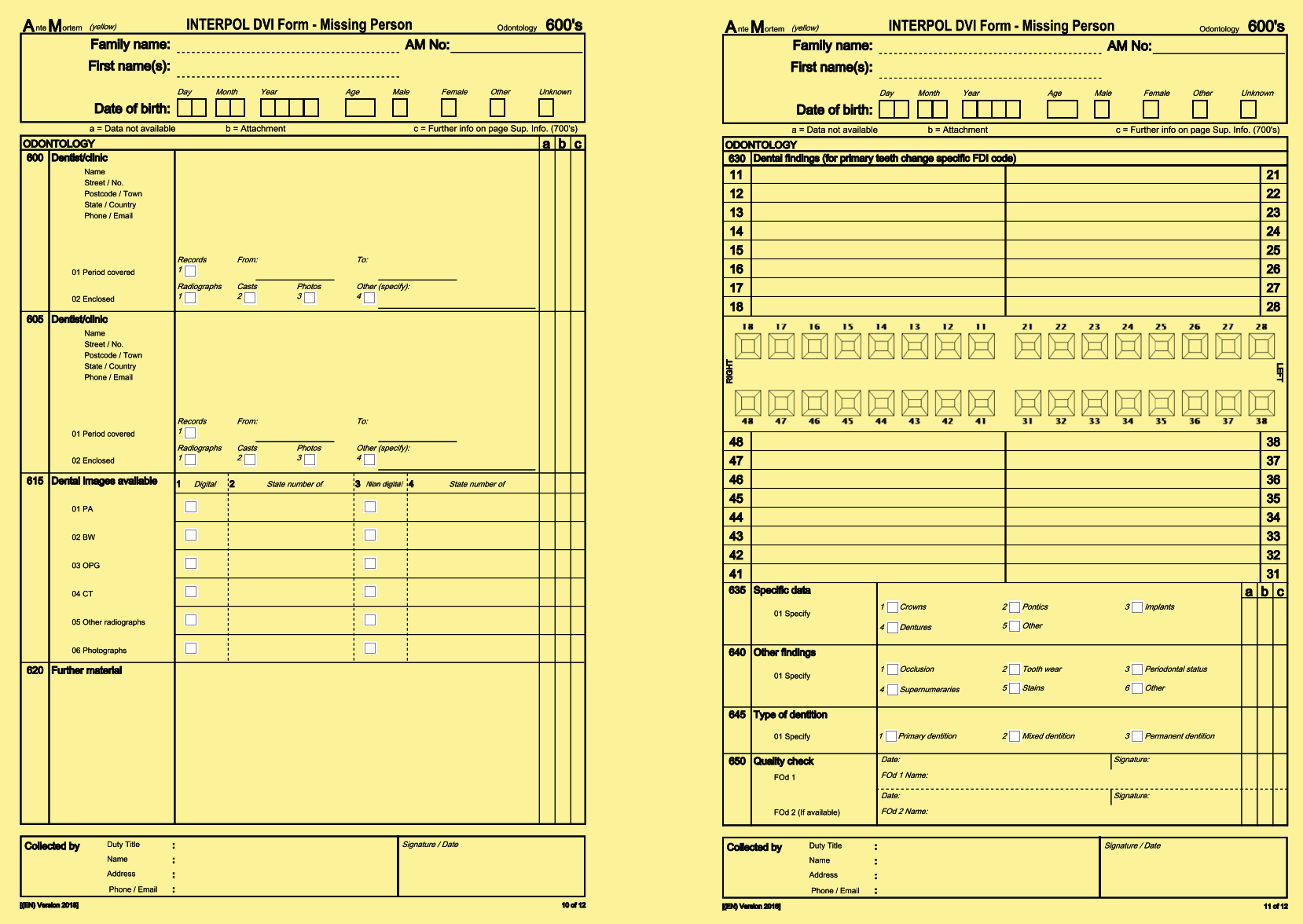

Fig. 2 (continued)

included measurements of the pulp size on radiographs since a reduction in pulp size can be seen with advancing age [24]. The destructive method used a photograph of a sectioned premolar. An increase in the apical translucent zone can be measured on teeth with advancing age. This method is often used in identification and age estimations of human remains (Bang's method) [25].

The students were asked to perform the age assessments and enter their answers into the LMS (Canvas). Their assessments were immediately indicated as right or wrong within a reasonable age span using a numerical range in the Canvas Quizzes function. Each assignment was discussed before the students advanced to the next exercise.

\section{Background story}

To make both practical exercises more realistic, a fictional story was presented for the students. The accident was a wedding celebration in a cave where all participants were poisoned by carbon monoxide from a generator due to poor ventilation - an incident that ended fatally for some of them. The students formed an identification team that was asked to identify the deceased and estimate the age for some of the victims.

\section{Implementation of the practical exercises}

Both practical exercises started with a 45-min introductory lecture, repeating the most relevant theoretical principles needed to perform the exercises. The lecturers explained the purpose of each exercise. The students worked in pairs using their laptops, solved each exercise and uploaded their answers into Canvas. Teachers in FO were available for assistance while the students worked with the exercises. When all tasks were completed and registered, the exercises were reviewed in a plenary session to ensure the students' highest cognitive skills in educational taxonomy [26].

\section{Evaluation}

Fifty-five dental students attended the practical exercises. The response rates of a questionnaire on students' satisfaction with the practical exercises were $80 \%$ and $73 \%$ for identification and age estimation respectively. The students 

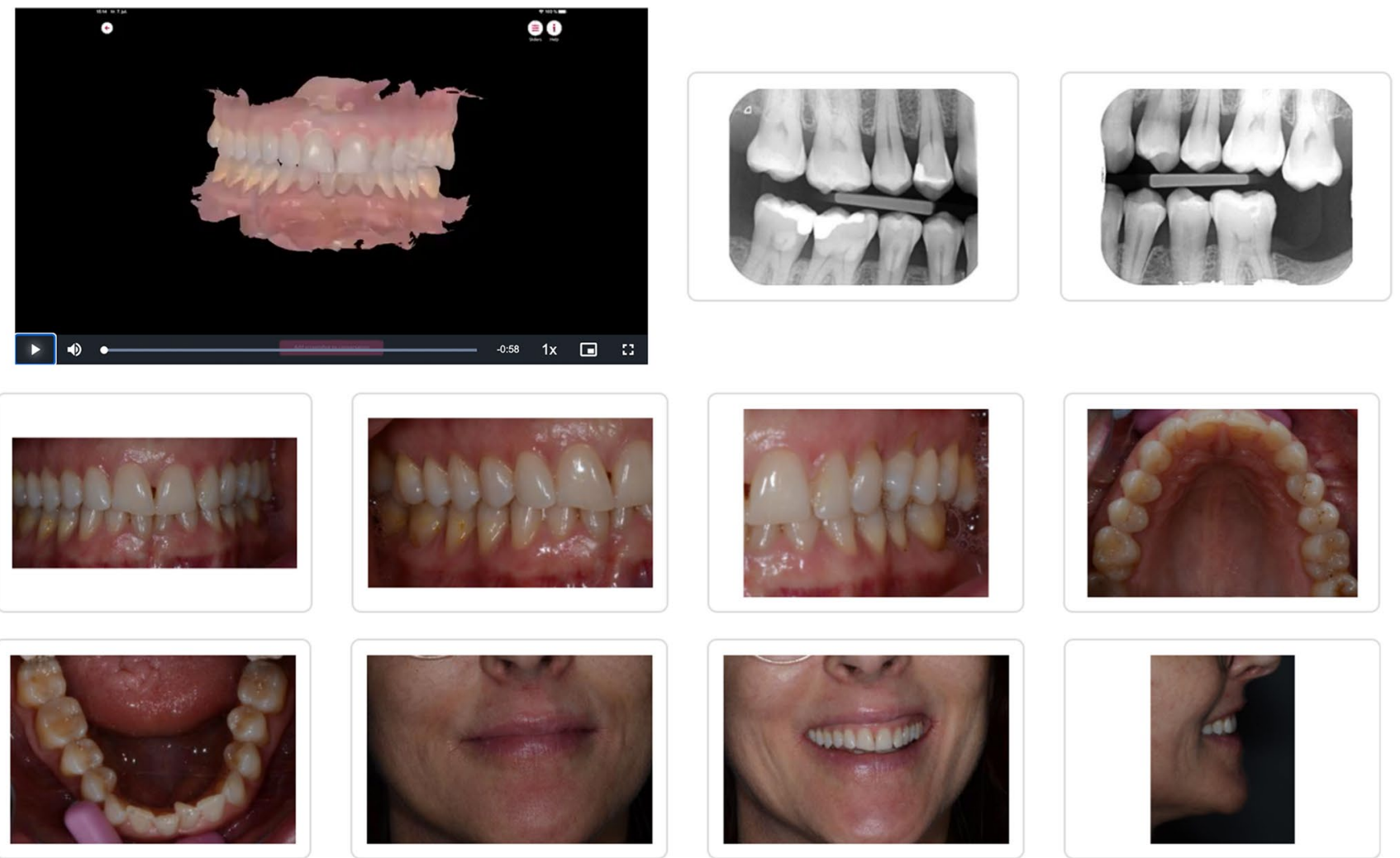

Fig. 3 a PM information package as presented for the students; newly performed bitewing radiographs, intraoral pictures, video clips of the IOS scan. b Interpol form, disaster victim identification, unidentified human remains postmortem.

generally rated all aspects of the new teaching methods as high. Some students indicated that they had software compatibility problems when using other operating systems than Windows. Some general comments on digital teaching were submitted.

\section{Discussion}

The present paper describes the digitalisation and implementation of practical exercises on dental identification and age assessment. The introduction of FO to dental students is essential as dentists may serve a critical humanitarian function by supplying local communities with forensic resources [27]. FO teaching in the undergraduate curriculum is best suited to the final year when the students' knowledge in dental morphology, pathology, radiology and clinical dentistry has evolved. The exercises allow students to consolidate their learning outcomes. Teaching of FO varies significantly among dental schools around the world. The lack of teaching resources or differences in the offered training in FO may introduce inequalities between dentists.

It is complicated to bring a class into a mortuary for ethical, legal and practical reasons. Restrictions in the number of students allowed to be in the morgue, in the number of bodies available for identification purposes, and restrictions related to the confidentiality of the diseased hamper such a teaching method. Even small, selected groups may disrupt routines and permission for a visit may not be granted.

Ideally, all students should have the opportunity to perform a dental PM examination in a morgue representing a realistic approach to forensic sciences. Important traits in the dentition may only be detectable by physical examination like probing, and this aspect cannot fully be represented by a digital method. Nevertheless, the combination of intraoral scanning presented as a film, intra-oral pictures and radiographs will in most cases reveal even dental restorations without radio-opacity. The digital material does not represent a perfect solution, but is close enough to reality for undergraduate dental students.

Digital material like the one presented in this paper can be used in any LMS and reduces the need for human resources. The difficulty level in matching material can also be adjusted according to the participants' level of knowledge. The material can be translated and expanded to be used in postgraduate courses.

The undergraduate FO course curriculum in dentistry may also include an introduction to forensic medicine, crime 

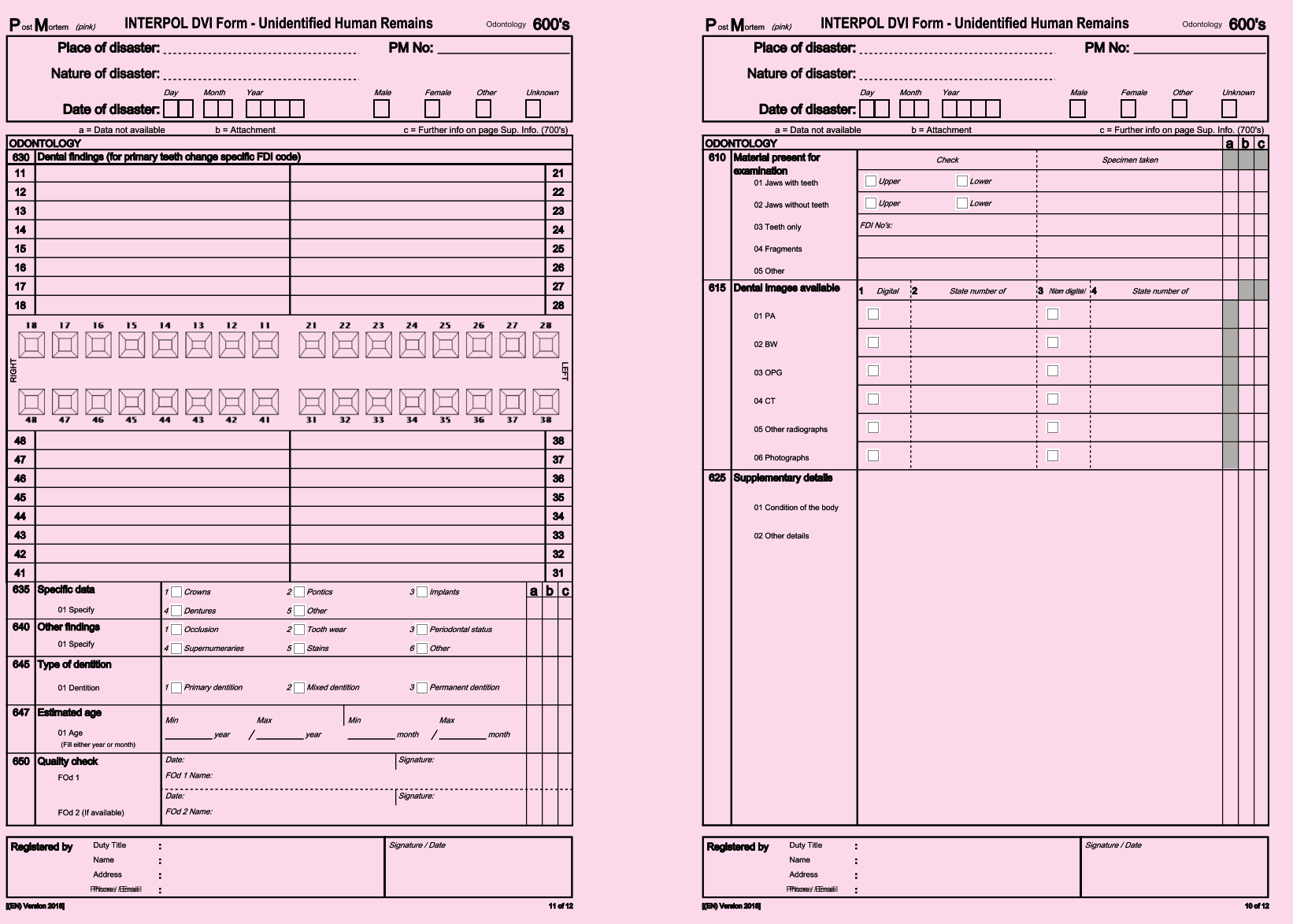

Fig. 3 (continued)

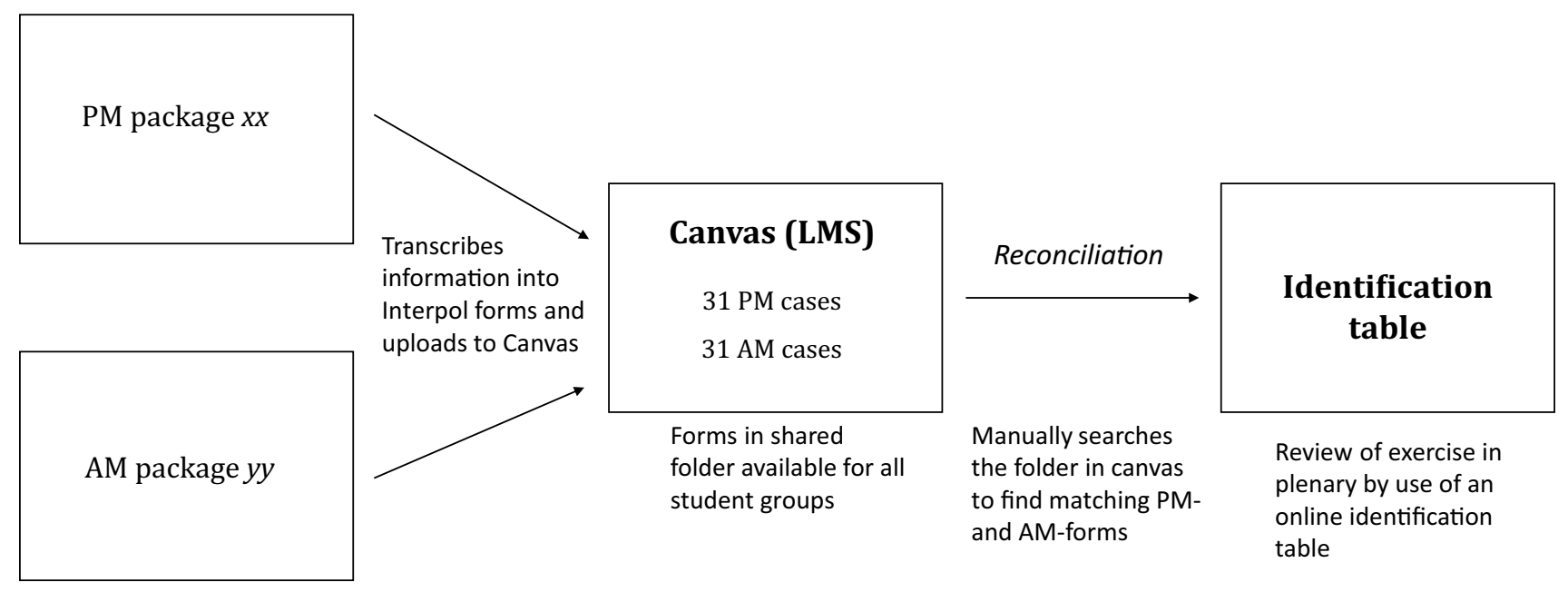

Each student group randomly receives a PMand an AM-package

Fig. 4 A simplified flow diagram of the exercise in identification 
Table 1 Methods for ageassessment

\begin{tabular}{lll}
\hline Age group & Material & Method \\
\hline Children & Panoramic radiographs & Demerijan, London Atlas ([20] [21]) \\
Sub-adults & Panoramic radiographs & Lee, Haavikko ([22, 23]) \\
Adults & $\begin{array}{l}\text { Periapical radiograph of upper left central } \\
\text { incisor }\end{array}$ & Kvaal ([24]) \\
Dead & Ground section of lower premolar & Bang ([25]) \\
\hline
\end{tabular}

investigation, legal aspects and research, including practical experience in dental identification and dental age estimation [3]. A brief introduction to other forensic disciplines and how FO links with the wider forensic community may be included. The students get an impression of a dental PM examination and the importance of identification for the deceased's family and society.

\section{Identification}

Active participation in forensic odontology is for the selected few, but the concept and the understanding of the principle are essential for any practicing dentist. This enables the dentist to explain to relatives of the deceased the need for handing over the dental records to the police or other investigative agency. Likewise, the practitioner will understand the need for the submission of all recorded material. The late timing in the curriculum will also cement the understanding of why it is essential to keep accurate dental records and the importance of well-written records [27].

\section{Dental age assessments}

Any dental practitioner may be asked to assess the development of a child's teeth using available charts. These will give a rough estimate of normal development and may be sufficient to calm an anxious parent. In legal and other contexts such as sports, a more accurate assessment may be required. The students must understand the possibilities and limitations of different methods of age assessment, the biological variations in tooth development and the implications in legal matters.

Age assessments are multi-professional topics and open for cooperation between different disciplines. The variation in tooth development timing may be a question raised. The dentist ought to know how dental development can be assessed relative to chronological age for people without birth documents. Deciding whether he or she is a minor or an adult is relevant to the rights related to age in western societies.

Age estimations have been at the centre of controversies because there is no consensus on how such estimations should be performed and interpretated. The biological variation in age assessment is demonstrated in the exercises [28-30]. Evaluation of age assessment methods has been the topic of master theses, and the course may be an introduction to $\mathrm{PhD}$ research projects.

\section{Intraoral scans}

Many general dental practitioners and prosthodontists use IOS as a diagnostic tool. It provides a virtual impression of the dentition and sometimes the whole oral cavity. Digital scanners are classified as medical equipment [31]. In our practical exercises, we used a 3D model constructed from a complete digital scan of the dentition as a model for PM examination. To our knowledge, the use of IOS is a new approach to visualise PM for educational purposes. It serves its purpose perfectly by being minimally time-consuming and neither exposing the patients to ionising radiation nor a complicated procedure. IOS has been shown to provide higher patient comfort than regular alginate impressions, but still maintaining a similar degree of accuracy [32, 33].

Making a film of the 3D scanning does not fully represent a PM examination. It cannot replace all the information a trained forensic odontologist can draw from a corpse, but serves as an introductory tool. An additional aspect in 3D scanning, not evaluated in the present study, is the capturing of the soft-tissue topography and morphological information, such as the palatal rugae. Traits like these can have high power in deduction related to sexual dimorphism and forensic identification [34, 35].

\section{Digital teaching}

Blended or hybrid learning was implemented in these practical exercises. Blended learning entails integrating face-toface interaction and technologically mediated interaction between students, teachers and learning resources [36, 37]. This is in line with Manica et al.'s statements that teaching forensic odontology has gone from blackboard to webinars [38]. Face-to-face lectures and technology may be combined with blended learning and virtual classrooms. Better accessibility, affordability, and more flexibility are some of the benefits of hybrid learning [39]. Digital access may increase students' learning potential since all students could be actively involved. 
With fully digital teaching, the students can learn anytime and anywhere, thereby developing new skills leading to life-long learning. It has been stated that students are more available mentally in a lecture theatre [40]. The evaluation confirmed that the students find the educational material in FO applicable in a fully digital platform, but simultaneously appreciate the teachers' presence. It has also been confirmed in other evaluations that dental students viewed online learning as a supplement rather than a replacement of traditional teaching methods [41].

Combining the sectioning of a tooth with digitalised measurement tools and scanning analogue panoramic radiographs presented some challenges. Different computer-monitor sizes, resolutions and other qualities impaired diagnostic accuracy and results. The ambient light varies for the different workplaces of the students. Those are well-known challenges when working with digital radiographs [42, 43]. A standardised test may be considered to calibrate monitor settings to avoid image presentation inconsistencies on different devices. Such a test tool is provided by the American Association of Physicists in Medicine [44].

A consequence of the Covid 19 pandemic was an immediate transition to digital education in all theoretical parts of the dental subjects. Digital education is an essential tool to maintain social distance in education and take advantage of asynchronous learning [45]. It cannot replace the clinical part of dental education, which is crucial when educating a practitioner, but it can complement clinical teaching.

\section{Future perspectives}

Augmented reality in 3D visualisation could be a prospect for dental education, enhancing insight in tooth morphology, position, occlusion and facilitating treatment planning [31]. Digital technologies also include the 3D printing of virtual teeth, which provides transparency for all students due to identical setups. This can be used to explain biomimetic dentistry, important in conservative dentistry and prosthodontics, but, as shown in this paper, could also be a valuable tool in FO identification cases.

Implementing new information or updating the database is easy. The level of difficulty may be adjusted by adding or removing cases. The material can easily be transformed into webinars. To fulfil an international application and enhance inter-university collaboration, the exercises may, in time, be translated into English, contributing to the education of international forensic odontologists.

\section{Conclusion}

The digital educational material in FO embraces new possibilities for digital teaching, intraoral scanning and new strategies ensuring patient anonymity. In addition, it preserves the copyright of the authors. It provides a flexible learning environment and allows all the students to take a more active part in the exercises.

The material can be implemented in any LMS and any video conference platform. It is applicable for both underand postgraduate students as a blended/hybrid or fully online course. The digitalisation of smaller topics like FO, which have unequal teaching resources in different dental schools, opens the possibility of providing more students the required knowledge without excessive expenses.

Funding Open access funding provided by University of Oslo (incl Oslo University Hospital)

\section{Declarations}

Ethical approval The implementation of the present teaching material was approved by the Regional Committee for Medical Research Ethics in Norway (ID: 2019/460 D).

Informed consent Written informed consent was obtained from the participants following the Helsinki Declaration of 1964 and its later amendments.

Consent for publication Along with the data collection, participants consented for use of their data for academic research including publications if the anonymity is maintained and their information is not shared or disclosed to a third party. The making of the material does not involve research with human participants and/or animals and the participants only consented to the use of collected dental information and some in addition had their extraoral photos taken or an intraoral scanning, involving no exposure to radiation.

Conflict of interest The authors declare no competing interests.

Open Access This article is licensed under a Creative Commons Attribution 4.0 International License, which permits use, sharing, adaptation, distribution and reproduction in any medium or format, as long as you give appropriate credit to the original author(s) and the source, provide a link to the Creative Commons licence, and indicate if changes were made. The images or other third party material in this article are included in the article's Creative Commons licence, unless indicated otherwise in a credit line to the material. If material is not included in the article's Creative Commons licence and your intended use is not permitted by statutory regulation or exceeds the permitted use, you will need to obtain permission directly from the copyright holder. To view a copy of this licence, visit http://creativecommons.org/licenses/by/4.0/. 


\section{References}

1. EE Herschaft RH Rasmussen 1978 The teaching of forensic dentistry: a status report J Dent Educ 4295326

2. Wikipedia, Forensic dentistry, https://en.wikipedia.org/wiki/Foren sic_dentistry, accessed March 02, 2021.

3. AB Acharya 2006 Teaching forensic odontology: an opinion on its content and format European Journal of Dental Education 10 3137141

4. G Johanson AJ Drinnan S Keiser-Nielsen 1981 Education in forensic odontology Int Dent J 311613

5. DK Whittaker 1971 The teaching of forensic odontology to the undergraduate Br Dent J 1315199200

6. KP Hermsen JD Johnson 2012 A model for forensic dental education in the predoctoral dental school curriculum Journal of Dental Education 765553561

7. Interpol, Disaster victim identification (DVI), https://www.inter pol.int/en/How-we-work/Forensics/Disaster-Victim-IdentificationDVI accessed March 3, 2021.

8. Thevissen, P. and H. Liversidge, Chapter 6.1 dental age estimation based on tooth development, in Textbook of Forensic Odontostomatology by IOFOS. 2020, Naklada Slap.

9. Kvaal, S.I., Chapter 6.2 dental age assessment in adults, in Textbook of Forensic Odonto-stomatology by IOFOS. 2020, Naklada Slap.

10. DC Stoeckel PJ Merkley J McGivney 2007 Forensic dental training in the dental school curriculum Journal of Forensic Sciences 523684686

11. PA Pullon GE Gantner 1974 Teaching forensic odontology in a dental school Forensic Science 43201206

12. General, D.P.R., Regulation (EU) 2016/679 (General Data Protection Regulation) version of the OJ L 119, 04.05.2016; cor. OJ L 127, 23.5.2018, https://gdpr-info.eu/ accessed March 3, 2021.

13. RM Mizumoto B Yilmaz 2018 Intraoral scan bodies in implant dentistry: a systematic review The Journal of Prosthetic Dentistry 1203343352

14. S Logozzo 2014 Recent advances in dental optics - Part I: 3D intraoral scanners for restorative dentistry Optics and Lasers in Engineering 54203221

15. Mangano, F.G., et al., Trueness of 12 intraoral scanners in the full-arch implant impression: a comparative in vitro study. BMC Oral Health, 2020. 20(1).

16. Turk, G. The PLY Polygon File Format. http://www.dcs.ed.ac.uk/ teaching/cs4/www/graphics/Web/ply.html accessed June 21, 2021.

17. F Mangano 2017 Intraoral scanners in dentistry: a review of the current literature BMC Oral Health 171149

18. Rasband, W.S., ImageJ, U. S. National Institutes of Health, Bethesda, Maryland, USA, https://imagej.nih.gov/ij/, 1997-2018.

19. GeoGebra, T.I.G.I., GeoGebra Math Apps, https://www.geogebra. org/, accessed March 3, 2021.

20. A Demirjian H Goldstein JM Tanner 1973 A new system of dental age assessment Human Biology 452211227

21. SJ Alqahtani MP Hector HM Liversidge 2010 Brief communication: the London atlas of human tooth development and eruption American Journal of Physical Anthropology 1423481490

22. S-H Lee 2009 Development of third molars in Korean juveniles and adolescents Forensic Science International 188 1-3 107111

23. K Haavikko 1974 Tooth formation age estimated on a few selected teeth. A simple method for clinical use Proc Finn Dent Soc 701 159

24. SI Kvaal 1995 Age estimation of adults from dental radiographs Forensic Science International 743175185
25. G Bang E Ramm 1970 Determination of age in humans from root dentin transparency Acta Odontologica Scandinavica 281335

26. Bloom, B., Taxonomy of educational objectives: the classification of educational goals. Handbook 1:Cognitive Domain. 1st Ed. New York, NY: David McKay Co, Inc. 201 p., 1956.

27. A Soon J Graham R Bassed 2019 Teaching of forensic odontology in basic dental programmes in nine Australian dental schools: a survey European Journal of Dental Education 233244250

28. A Schmeling 2008 Criteria for age estimation in living individuals International Journal of Legal Medicine 1226457460

29. A Schmeling 2016 Forensic age estimation: methods, certainty, and the law Deutsches Aerzteblatt Online 11344450

30. E Cunha 2009 The problem of aging human remains and living individuals: a review Forensic Science International 193 1-3 113

31. NU Zitzmann 2020 Digital undergraduate education in dentistry: a systematic review International Journal of Environmental Research and Public Health 1793269

32. A Ender T Attin A Mehl 2016 In vivo precision of conventional and digital methods of obtaining complete-arch dental impressions The Journal of Prosthetic Dentistry 1153313320

33. C Berntsen 2018 Clinical comparison of conventional and additive manufactured stabilization splints Acta Biomaterialia Odontologica Scandinavica 418189

34. RNM Andrade 2019 Reliability of palatal rugoscopy for sexual dimorphism in forensic dentistry: a systematic literature review and meta-analysis Archives of Oral Biology 972534

35. A Paliwal S Wanjari R Parwani 2010 Palatal rugoscopy: establishing identity Journal of forensic dental sciences 212731

36. BJ Mcgarry 2015 Flexible learning design in curriculum delivery promotes student engagement and develops metacognitive learners: an integrated review Nurse Education Today 359966973

37 T Jowsey 2020 Blended learning via distance in pre-registration nursing education: a scoping review Nurse Education in Practice 44102775

38. S Mânica L Gorza 2019 Forensic odontology in the 21 st century - identifying the opinions of those behind the teaching Journal of Forensic and Legal Medicine 64713

39. S Dhawan 2020 Online learning: a Panacea in the Time of COVID-19 Crisis Journal of Educational Technology Systems 491522

40. Juul, F.E., Digitale forelesninger. Tidsskrift for Den norske legeforening, 2020.

41. MA Asiry 2017 Dental students' perceptions of an online learning The Saudi Dental Journal 294167170

42. K Hellén-Halme 2008 Effect of ambient light and monitor brightness and contrast settings on the detection of approximal caries in digital radiographs: an in vitro study Dentomaxillofac Radiol 37 73804

43. A Butt M Mahoney N Savage 2012 The impact of computer display performance on the quality of digital radiographs: a review Australian Dental Journal 571623

44. E Samei 2005 Assessment of display performance for medical imaging systems: Executive summary of AAPM TG18 report Medical Physics 32412051225

45. SJ Daniel 2020 Education and the COVID-19 pandemic PROSPECTS 49 1-2 9196

Publisher's note Springer Nature remains neutral with regard to jurisdictional claims in published maps and institutional affiliations. 